\title{
CMEARTICLE
}

\section{Clinics in diagnostic imaging (159)}

Vijay $\underline{\text { Krishnan }}^{1}, \mathrm{MD}, \mathrm{FRCR}$, Ashish $\underline{\text { Chawla }}^{1}, \mathrm{MD}, \mathrm{DABR}$, Eric $\underline{\text { Wee }}^{2}, \mathrm{MBBS}, \mathrm{MRCP}$, Wilfred $\mathrm{CG} \underline{\mathrm{Peh}}{ }^{1}$, FRCP, FRCR

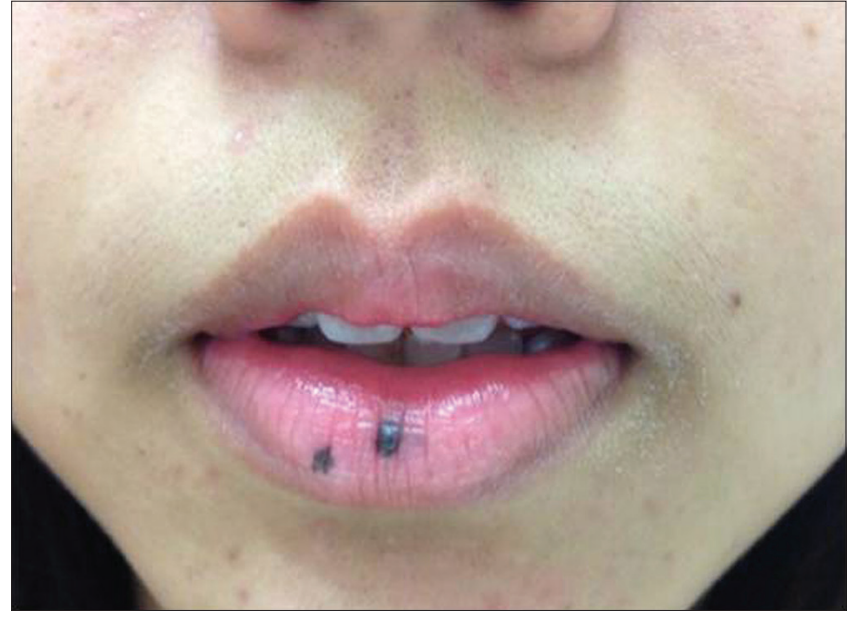

Fig. 1 Clinical photograph of the patient's mouth.

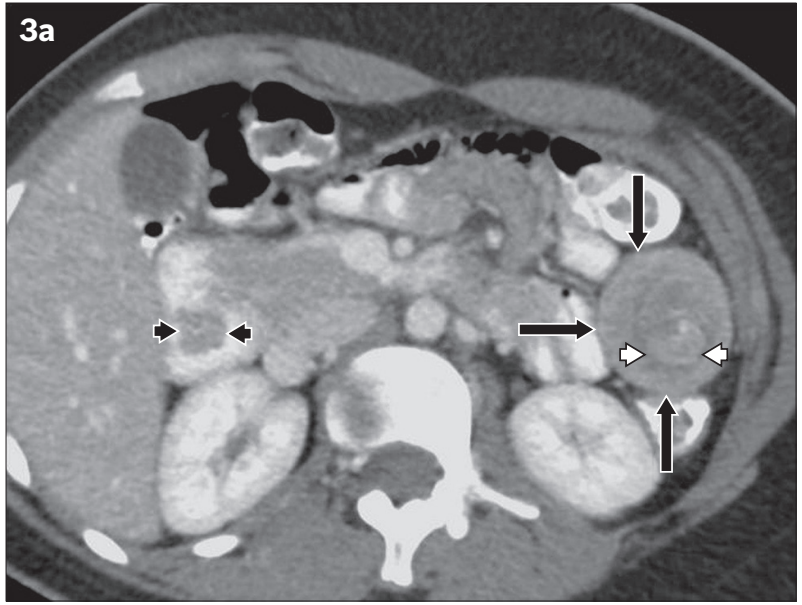

Fig. 3 (a) Axial and (b) coronal CT images of the abdomen.

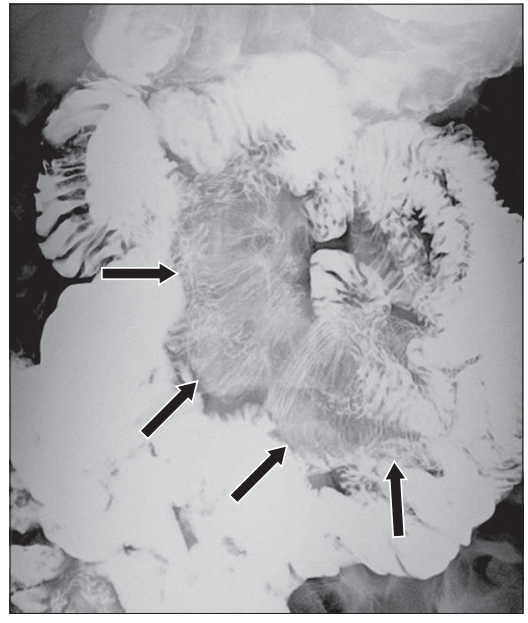

Fig. 2 Barium meal and follow-through image.

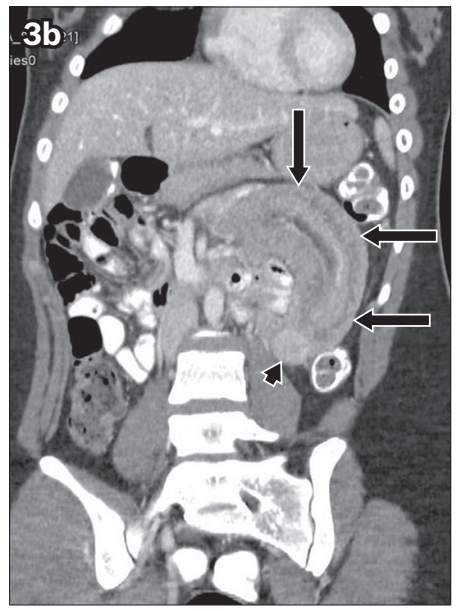

\section{CASE PRESENTATION}

A 21-year-old woman presented to the accident and emergency department with an acute onset of upper abdominal pain. The patient had similar and recurrent episodes of upper abdominal pain for the past six months. One month before this presentation, she had an episode of melaena with abdominal pain, which was clinically diagnosed as gastritis/bleeding ulcer and treated with anti-ulcer medications. On clinical examination, the patient was noted to have multiple lip pigmentations (Fig. 1). What do the barium meal and follow-through series (Fig. 2) and computed tomography (CT) (Fig. 3) show? What is the diagnosis? 

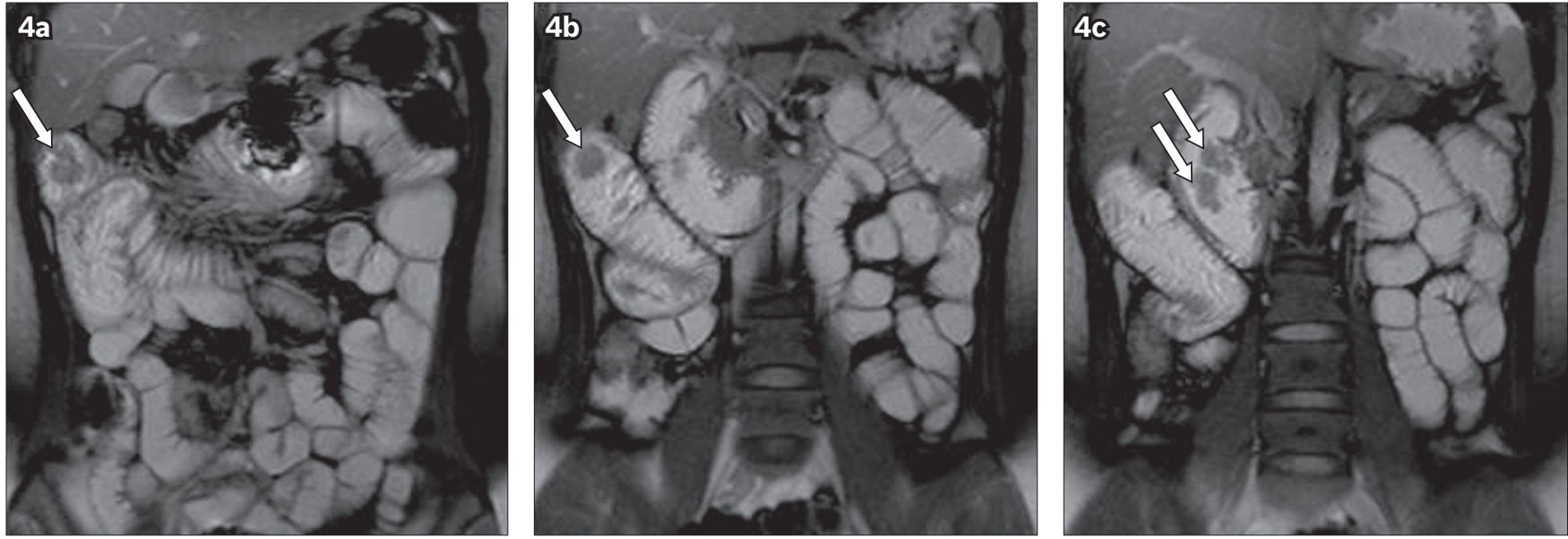

Fig. 4 Coronal MRE images show (a \& b) multiple jejunal polyps (arrows), and (c) a lobulated duodenal polyp (arrows).
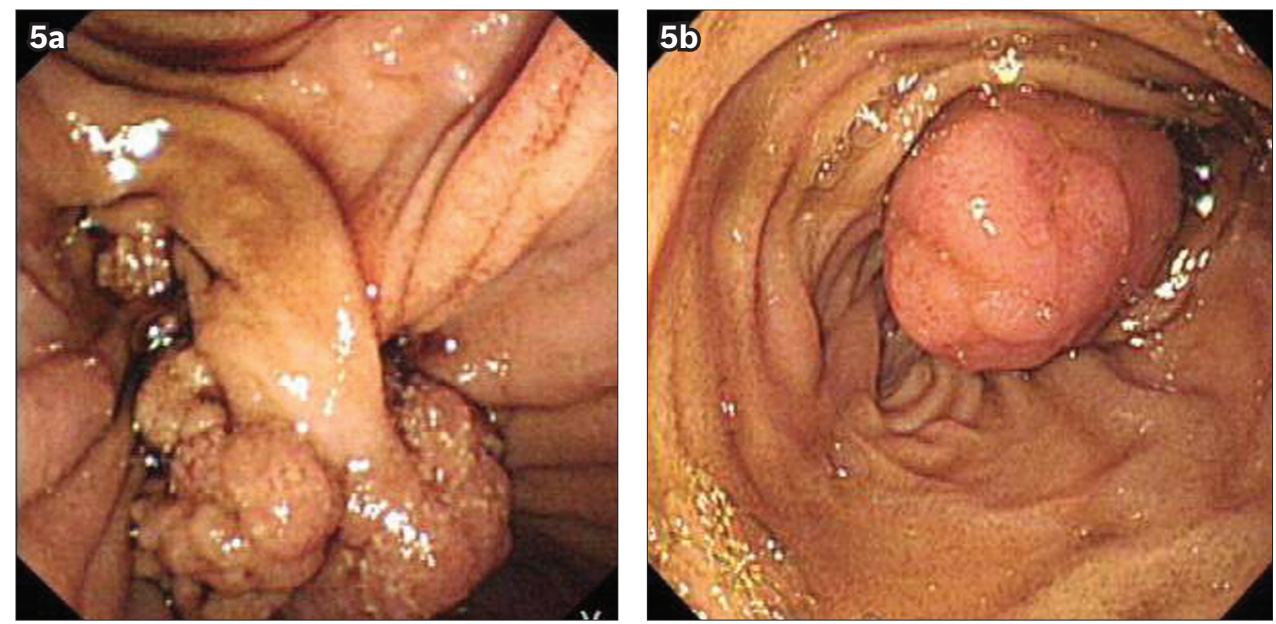

Fig. 5 Upper gastrointestinal endoscopic images show (a) a polyp in the second part of the duodenum, attached to the duodenal wall by a prolapsed short stalk, and (b) a polyp in the jejunum.

\section{IMAGE INTERPRETATION}

Barium meal and follow-through series (Fig. 2) shows the coiledspring appearance of dilated jejunal loops (arrows). Axial CT image (Fig. 3a) shows a loop of jejunum (white arrowheads) within another loop of dilated jejunum, producing a bowel-within-bowel or 'target' appearance (black arrows). A lobulated polyp (black arrowheads) is visualised within the lumen of the duodenum. Coronal CT image (Fig. 3b) shows another enhancing polyp (arrowhead) at the apex of the jejunal intussusception (arrows). Mesenteric fat and enhancing vessels are noted within the intussuscepted jejunal loop.

\section{DIAGNOSIS}

Jejunal intussusception due to Peutz-Jeghers syndrome.

\section{CLINICAL COURSE}

Magnetic resonance enteroclysis (MRE) was performed on the patient one week after CT. MRE showed multiple jejunal and duodenal polyps (Fig. 4). Intussusception was not seen at the time of study; this is consistent with transient intussusception. Upper gastrointestinal endoscopy revealed a fleshy polyp measuring 3-4 cm in the second part of the duodenum (Fig. 5a), attached by a prolapsed short stalk. There were two pedunculated polyps in the jejunum (Fig. 5b) within $1 \mathrm{~cm}$ of each other. Histopathology of the biopsies of duodenal and jejunal polyps revealed hyperplastic glandular epithelium with the glands separated by compact smooth muscle bundles, consistent with Peutz-Jeghers polyps. There was no evidence of high-grade dysplasia or malignancy. The patient was scheduled for outpatient follow-up.

\section{DISCUSSION}

Peutz-Jeghers syndrome, first described by Peutz in 1921 and by Jegher in 1944, is characterised by hamartomatous polyps of the gastrointestinal tract (GIT) and mucocutaneous perioral pigmentation. It is an autosomal dominant inherited syndrome with incomplete penetrance, and its reported incidence is 1 in 150,000 births. Mutation of the tumour suppressor gene serine/ threonine kinase 11, located on chromosome 19p13.3, is associated with Peutz-Jeghers syndrome. Spontaneous mutations give rise to some cases. ${ }^{(1-4)}$ Lip and buccal mucosae are common locations for mucocutaneous pigmentations. The eyelid, dorsal aspect of the fingers and sole of the foot are less common locations. They are usually not seen at birth and appear by the first or second year of life. Skin and lip lesions disappear by adulthood, whereas buccal lesions remain. ${ }^{(5)}$

Peutz-Jeghers polyps can occur anywhere in the GIT except the oesophagus, and they are most commonly seen in 


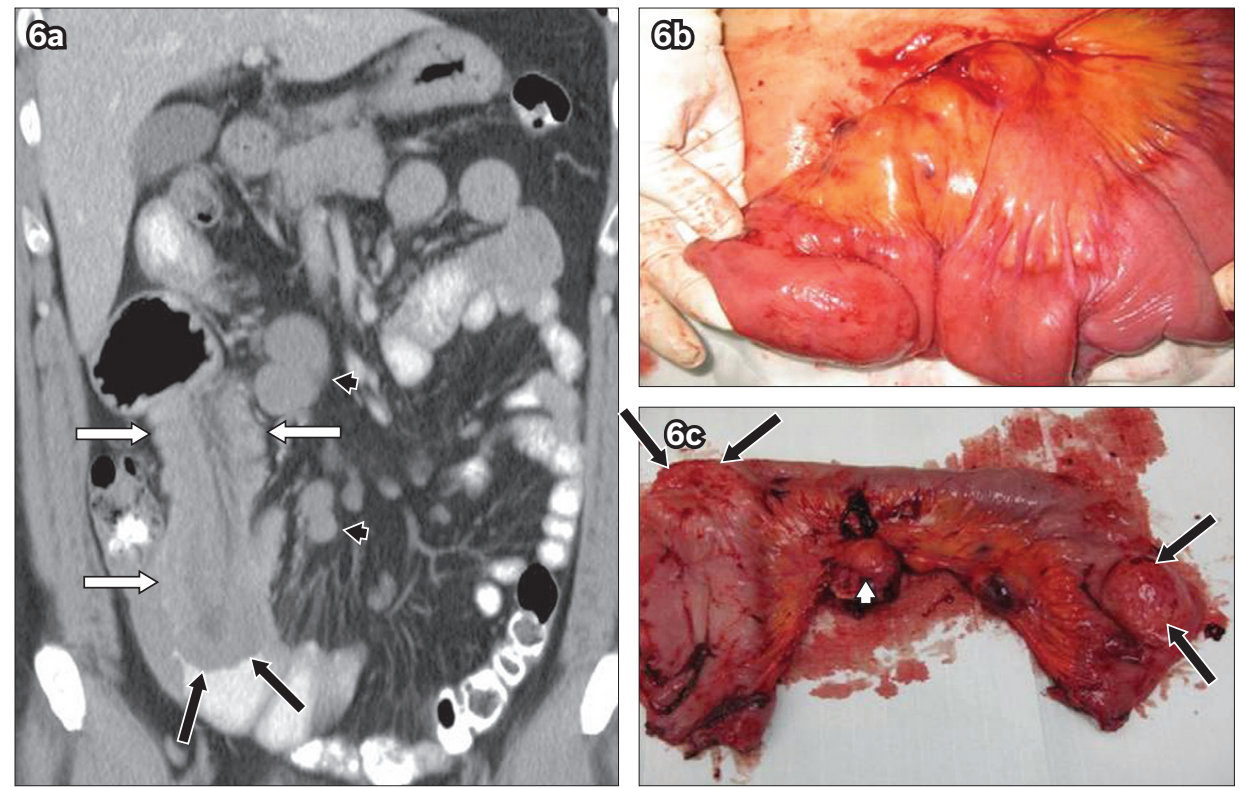

Fig. 6 Small bowel lymphoma with intussusception in a 50-year-old man who presented with colicky abdominal pain. (a) Coronal CT image shows small bowel intussusception (white arrows) and smoothwalled eccentric lesions in the small bowel (black arrows). Multiple enlarged mesenteric lymph nodes are present (arrowheads). The presence of homogeneously enhancing lymph nodes points to the imaging diagnosis of lymphoma. ( $b$ \& $c$ ) Postoperative photographs of the resected specimen show two bulky small bowel lesions (arrows) and mesenteric lymph nodes (arrowhead). Histopathology of the lesions confirmed the diagnosis of lymphoma.

the jejunum, followed by the ileum. The hamartomas in this syndrome are unique in that they have a characteristic smooth muscle core arising from the muscularis mucosae, which extends to the polyp. These polyps frequently present with recurrent abdominal pain due to intussusception. Intussusceptions often reduce spontaneously. They may cause intestinal obstruction if reduction does not occur. Ulceration of polyps may lead to bleeding or chronic anaemia. Other rare sites that develop polyps include the kidneys, ureter, nasal passages and bronchial tree..$^{(4,6,7)}$ Imaging usually shows multiple polyps and it is unusual to see only a solitary polyp. Large polyps have a lobulated appearance. ${ }^{(5)}$ Polyps are often detected in barium studies, although they can also be seen in CT or ultrasonography (US). MRE can be used for the detection of polyps and has the advantage of a lack of ionising radiation. It has been shown that, for polyps measuring more than $10 \mathrm{~mm}$ in diameter, MRE has equal sensitivity to video capsule endoscopy (VCE) ${ }^{(8)}$ Even though detection of small polyps is better with VCE, it cannot be used in the presence of obstruction. ${ }^{(9,10)}$

On radiography, intussusception may be seen as a soft tissue mass, commonly occupying the right upper quadrant. There may be a soft tissue mass containing concentric circular lucency (target sign) due to mesenteric fat in the intussusceptum. Another sign that may be identified is the meniscus sign, due to a crescent of air from the intussuscipiens outlining the intussusceptum at the apex of intussusception. Barium studies can demonstrate the meniscus sign (analogous to the radiograph) due to the projection of the intussusceptum into the barium-filled intussuscipiens at the apex. Barium may also reveal a 'coiled-spring' appearance of the bowel (i.e. coiled-spring sign) due to barium outlining the oedematous mucosal folds of the returning limb of the intussusceptum..$^{(4,11)}$ US typically reveals a 'pseudokidney' or 'doughnut' appearance, which consists of inner hyperechoic mesenteric fat that is dragged inside, between the entering and returning limbs of the intussusceptum and the outer hypoechoic rim, due to the oedematous wall of the intussuscipiens. ${ }^{(4,12)} \mathrm{CT}$ shows a 'bowelwithin-bowel' appearance of the intussusceptions, seen as a sausage-shaped mass along the longitudinal axis of the bowel and a target-shaped mass perpendicular to the long axis of the bowel (Fig. 3a). The inner loop of the bowel is separated from the outer loop by a crescent of fat-attenuation mesentery. Enhancing mesenteric vessels can be visualised (Fig. 3b)..$^{(4,13)}$

Patients with Peutz-Jegher syndrome have an increased risk of GIT malignancies, with an estimated risk of $2 \%-20 \%$. The stomach, duodenum and colon are the most common locations. Even though hamartomas are commonly seen in the small intestine, no definite malignant transformation has been established. There is also an increased risk for extraintestinal malignancies, with a prevalence rate of $10 \%-30 \%$. Common extraintestinal neoplasms include pancreatic, breast and reproductive organ (ovary, testis) tumours. ${ }^{(6)}$ Small bowel polyposis syndromes include hamartomatous polyposis syndromes (where predominantly hamartomatous polyps are present), familial adenomatous polyposis (FAP) syndrome (where predominantly adenomatous polyps are present) and hereditary mixed polyposis syndrome. Conditions such as lymphoma (Fig. 6), lymphoid hyperplasia, metastasis and multiple lipomas can present as multiple smooth-walled intraluminal masses in the small bowel, and mimic polyposis in the small intestine.

Hamartomatous polyposis syndromes (other than PeutzJeghers syndrome) include juvenile polyposis syndrome (JPS), Cowden syndrome, Bannayan-Riley-Ruvalcaba syndrome (BRRS), Proteus syndrome and Cronkhite-Canada syndrome. ${ }^{(1,6)}$ 

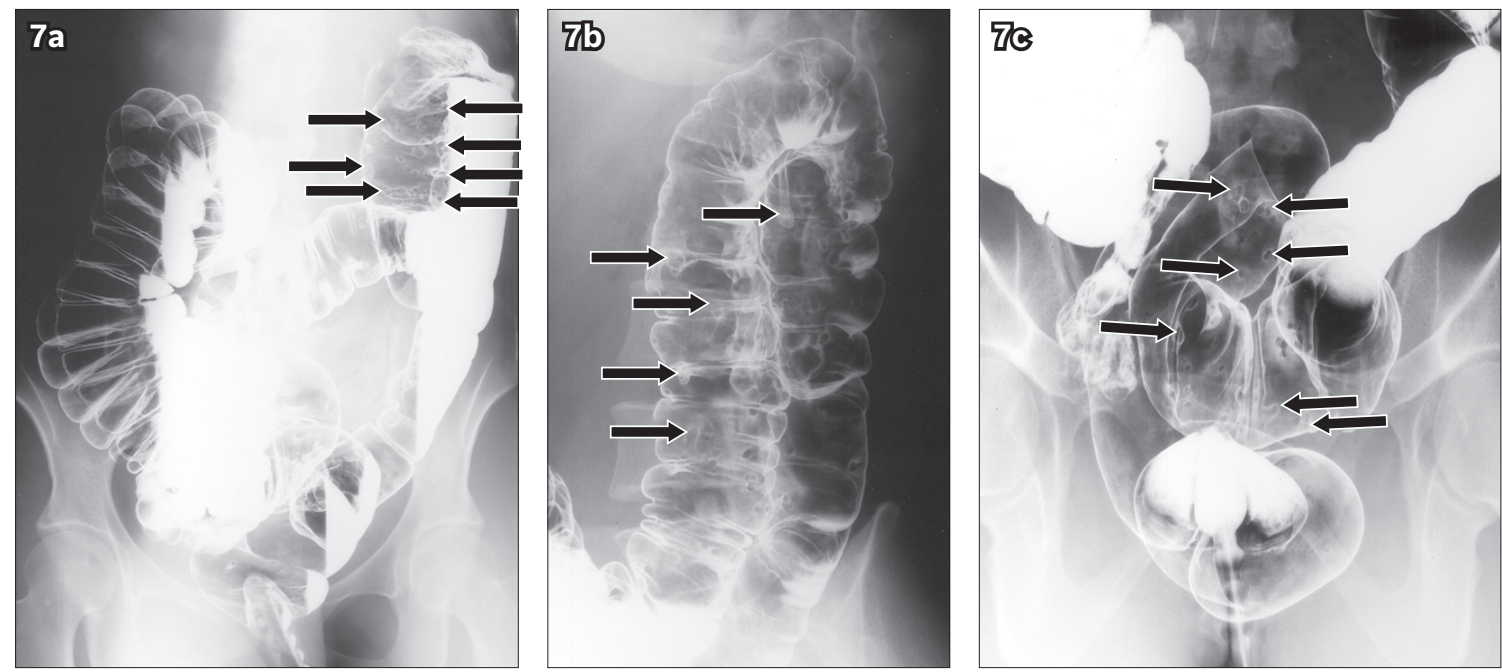

Fig. 7 Familial adenomatous polyposis syndrome in a 32-year-old woman who presented with bouts of bloody diarrhoea. (a-c) Barium enema images show multiple smooth and rounded filling defects scattered throughout the colon (arrows). The patient underwent prophylactic total colectomy.

An autosomal dominant disorder, JPS ${ }^{(1,6,14)}$ is characterised by multiple hamartomatous polyps that can occur anywhere in the GIT except the oesophagus. The rectosigmoid colon is the most common location. Extraintestinal manifestations associated with this syndrome include cardiac defect, pulmonary arteriovenous malformation, polydactyly, clubbing, intestinal malrotation, Meckel's diverticulum, macrocephaly, hypertelorism, cleft lip and palate, duplication of the renal pelvis and ureter, bifid uterus and vagina, undescended testes and supernumerary teeth. Patients with JPS have increased risk of colorectal, gastric and pancreatic carcinomas, and small intestinal adenocarcinoma. ${ }^{(1,14)}$

Cowden syndrome ${ }^{(6,15)}$ is an autosomal dominant trait. Patients with this syndrome may have facial or oral papillomas, fibromas and skin tumours, in contrast to the perioral pigmentation seen in patients with Peutz-Jeghers syndrome. Other associated extraintestinal manifestations are abnormalities of the thyroid (goitre, adenoma), breast (fibrocystic disease, fibroadenoma) and central nervous system (CNS) (Lhermitte-Duclos disease). Cancers associated with this syndrome are follicular carcinoma of the thyroid, breast (ductal) carcinoma, uterine carcinoma, and transitional cell carcinoma of the renal pelvis and urinary bladder. $\operatorname{BRRS}^{(6,16)}$ is an autosomal dominant syndrome characterised by multiple hamartomatous polyps of the small and large intestines, macrocephaly, pigmented lesions in the genital area, subcutaneous lipoma, visceral lipoma and haemangioma. Proteus syndrome ${ }^{(1,17)}$ is a multisystem disorder characterised by hamartomas of multiple tissues, epidermal and connective tissue nevi, hemihypertrophy, hyperostosis and various tumours. Associated tumours include various testicular tumours, cystadenoma of the ovary, CNS tumours and monomorphic adenoma of the parotid gland. Cronkhite-Canada syndrome ${ }^{(6,18)}$ differs from other polyposis syndromes in that it is not familial. In this syndrome, multiple small sessile polyps are noted throughout the GIT except the oesophagus. Patients may develop ectodermal abnormalities such as brownish macules on the palms and soles, and dystrophic nail changes. Cronkhite-Canada syndrome is associated with increased risk of colon and gastric cancers. ${ }^{(18)}$
$\mathrm{FAP}^{(19)}$ and its variants are autosomal dominant disorders caused by mutation involving the adenomatous polyposis coli gene located on chromosome $5 q 21$. Other variants of FAP include attenuated FAP (AFAP), Gardner's syndrome and Turcot's syndrome. In FAP (Figs. $7 \&$ 8), patients have innumerable polyps in the large bowel. After the colon, the duodenum is the second most common location for development of adenomas in FAP. Development of colorectal malignancies is inevitable (virtually $100 \%$ risk) without colectomy, and prophylactic surgery is usually performed by the end of the second decade or early third decade of life. Other associations of FAP include desmoid tumours, congenital retinal pigment hypertrophy and extracolonic malignancies. Extracolonic neoplasms associated with this syndrome are hepatoblastoma, and duodenal, gastric, ampullary, pancreatic, thyroid and CNS malignancies. In Gardner's syndrome, gastrointestinal polyps are associated with multiple osteomas, dental abnormalities (supernumerary and impacted teeth), skin (epidermal cysts, lipoma, fibromas and leiomyomas) and soft tissue tumours (desmoids and thyroid tumors). In Turcot's syndrome, gastrointestinal polyps are associated with primary CNS neoplasms, the commonest being medulloblastoma. AFAP is a variant of FAP, in which colonic polyps number less than 100 and are located in the proximal colon, with development of colorectal cancer at a later age compared to FAP. In hereditary mixed polyposis, ${ }^{(1)}$ mixed types of polyps, including atypical juvenile polyps, hyperplastic polyps, sessile serrated adenomas and adenomatous polyps, are present. This is associated with an increased risk of colorectal carcinoma. Although the imaging findings of polyps are not unique, the aforementioned associated findings discussed may help in the identification of the appropriate polyposis syndromes.

In summary, Peutz-Jeghers syndrome and other polyposis syndromes are associated with multiple GIT and extraintestinal malignancies. Knowledge of their clinical manifestations and early diagnosis of these syndromes is important so that early detection of future malignancies can be made through proper screening procedures, further complications may be avoided and appropriate management initiated. 

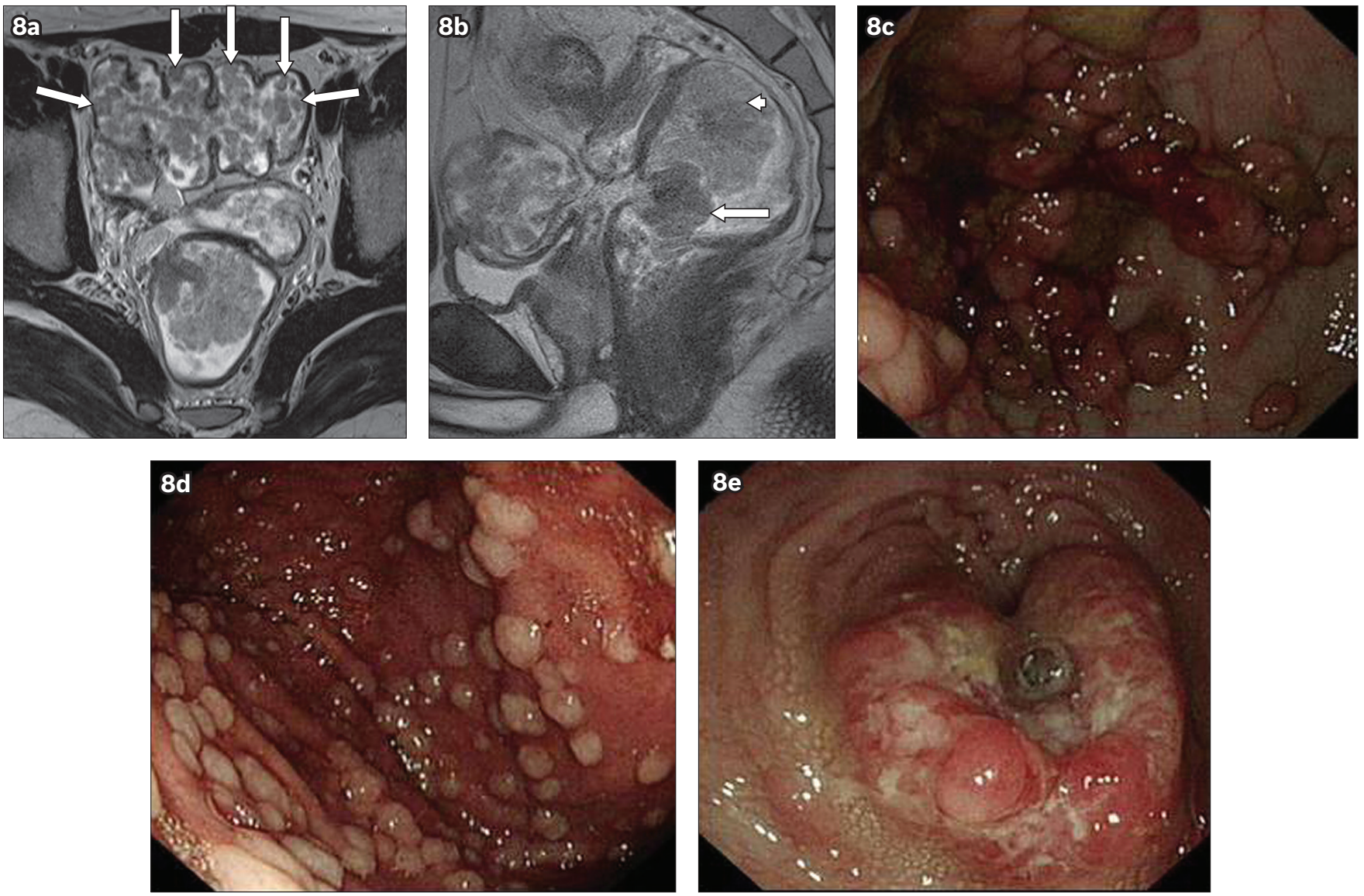

Fig. 8 Familial adenomatous polyposis syndrome in a 29-year-old man who was found to have rectal malignancy on routine follow-up. (a) Axial T2-W MR image shows multiple sigmoid polyps (arrows). (b) Sagittal T2-W MR image shows two large polypoidal lesions in the rectum (arrow) and rectosigmoid colon (arrowhead). Endoscopic images show multiple polyps in the (c) stomach; (d) colon; and (e) rectum. Biopsy of the rectal lesion confirmed an adenocarcinoma.

\begin{abstract}
A 21-year-old woman presented with acute onset of upper abdominal pain. A diagnosis of Peutz-Jeghers syndrome (PJS) was made based on the clinical picture of perioral pigmentation with imaging findings of transient jejunojejunal intussusceptions and small bowel polyps, and confirmed by characteristic histopathological appearances of Peutz-Jeghers polyps. PJS is a rare hereditary condition characterised by unique hamartomatous polyps, perioral mucocutaneous pigmentations, and increased susceptibility to gastrointestinal and extraintestinal neoplasms. Patients usually present with recurrent abdominal pain due to intussusception caused by polyps. Other modes of presentations include rectal bleeding and melaena. We describe the imaging findings of PJS and provide a brief review of bowel polyposis syndromes. The latter are relatively rare disorders characterised by multiple polyps in the large or small intestine, with associated risk of malignancies and other extraintestinal manifestations. Awareness of the manifestations and early diagnosis of these syndromes is crucial to prevent further complications.
\end{abstract}

Keywords: jejunojejunal intussusception, Peutz-Jeghers syndrome, small bowe polyposis syndromes, transient intussusception

\section{REFERENCES}

1. Arber N, Moshkowitz M. Small bowel polyposis syndromes. Curr Gastroenterol Rep 2011; 13:435-41.

2. Kutscher AH, Zegarelli EV, Rankow RM, Slaughter TW. Incidence of Peutz-
Jeghers syndrome. Am J Dig Dis 1960; 5:576-7

3. Rebsdorf Pedersen I, Hartvigsen A, Fischer Hansen B, et al. Management of Peutz-Jeghers syndrome. Experience with patients from the Danish Polyposis Register. Int J Colorectal Dis 1994; 9:177-9.

4. Rufener SL, Koujok K, McKenna BJ, Walsh M. Small bowel intussusception secondary to Peutz-Jeghers polyp. Radiographics 2008; 28:284-8.

5. Buck JL, Harned RK, Lichtenstein JE, Sobin LH. Peutz-Jeghers syndrome. Radiographics 1992; 12:365-78.

6. Harned RK, Buck JL, Sobin LH. The hamartomatous polyposis syndromes: clinical and radiologic features. AJR Am J Roentgenol 1995; 164:565-71.

7. Latchford A, Greenhalf W, Vitone LJ, et al. Peutz-Jeghers syndrome and screening for pancreatic cancer. Br J Surg 2006; 93:1446-55.

8. Gupta A, Postgate AJ, Burling D, et al. A prospective study of MR enterography versus capsule endoscopy for the surveillance of adult patients with PeutzJeghers syndrome. AJR Am J Roentgenol 2010; 195:108-16.

9. Caspari R, von Falkenhausen M, Krautmacher C, et al. Comparison of capsule endoscopy and magnetic resonance imaging for the detection of polyps of the small intestine in patients with familial adenomatous polyposis or with PeutzJeghers' syndrome. Endoscopy 2004; 36:1054-9.

10. Lazaraki G, Tzilves D, Parisi I, Tarpagos A. Magnetic resonance enteroclysis for Peutz-Jeghers syndrome. Ann Gastroenterol 2011; 24:219-220.

11. del-Pozo G, Albillos JC, Tejedor D, et al. Intussusception in children: current concepts in diagnosis and enema reduction. Radiographics 1999; 19:299-319.

12. Swischuk LE, Hayden CK, Boulden T. Intussusception: indications for ultrasonography and an explanation of the doughnut and pseudokidney signs. Pediatr Radiol 1985; 15:388-91.

13. Choi SH, Han JK, Kim SH, et al. Intussusception in adults: from stomach to rectum. AJR Am J Roentgenol 2004; 183:691-8.

14. Brosens LA, Langeveld D, van Hattem WA, Giardiello FM, Offerhaus GJ. Juvenile polyposis syndrome. World J Gastroenterol 2011; 17:4839-44.

15. Ravi Prakash SM, Suma GN, Goel S. Cowden syndrome. Indian J Dent Res 2010; 21:439-42.

16. Gorlin RJ, Cohen MM Jr, Condon LM, Burke BA. Bannayan-Riley-Ruvalcaba syndrome. Am J Med Genet 1992; 44:307-14

17. Zbuk KM, Eng C. Hamartomatous polyposis syndromes. Nat Clin Pract Gastroenterol Hepatol 2007; 4:492-502.

18. Samoha S, Arber N. Cronkhite-Canada syndrome. Digestion 2005; 71:199-200.

19. Galiatsatos P, Foulkes WD. Familial adenomatous polyposis. Am J Gastroenterol 2006; 101:385-98. 


\section{SINGAPORE MEDICAL COUNCIL CATEGORY 3B CME PROGRAMME} (Code SMJ 201502B)

Question 1. Regarding Peutz-Jeghers polyps:

True

False

(a) They are most commonly seen in the colon.

(b) They are unique in that they have a characteristic smooth muscle core.

(c) It is unusual to see only a solitary polyp.

(d) They are premalignant.

Question 2. Regarding Peutz-Jeghers syndrome:

(a) It commonly presents with rectal bleeding.

(b) Patients do not have an increased risk of gastrointestinal tract malignancies.

(c) Patients have an increased risk of pancreatic, breast and reproductive organ tumours.

(d) The eyelid, dorsal aspect of the fingers and sole of the foot are the most common locations of mucocutaneous pigmentations.

Question 3. Regarding imaging of intussusception:

(a) Radiography often shows a 'doughnut' appearance.

(b) Ultrasonography may reveal a 'pseudokidney' appearance.

(c) It may be seen as a sausage-shaped mass and target-shaped mass on CT.

(d) Barium meal and follow-through may reveal a 'coiled-spring' appearance of the bowel (coiled-spring sign).

Question 4. Regarding hamartomatous polyposis syndromes:

a) In juvenile polyposis syndrome, the rectosigmoid colon is the most common location of polyps.

b) Cronkhite-Canada syndrome is familial.

c) Patients with Cronkhite-Canada syndrome may develop ectodermal abnormalities such as brownish macules on the palms and soles, and dystrophic nail changes.

d) Lhermitte-Duclos disease is associated with Proteus syndrome.

Question 5. Regarding familial adenomatous polyposis syndrome:

(a) It is an autosomal dominant disorder.

(b) Polyps do not involve the small intestine.

(c) Prophylactic surgery is usually performed by the fifth decade of life.

(d) Gardner's syndrome is a variant of familial adenomatous polyposis, and is associated with medulloblastoma.

\section{Doctor's particulars:}

Name in full

MCR number

Email address

\section{SUBMISSION INSTRUCTIONS:}

(1) Log on at the SMJ website: http://www.sma.org.sg/publications/smjcurrentissue.aspx and select the appropriate set of questions. (2) Provide your name, email address and MCR number. (3) Select your answers and click "Submit".

\section{RESULTS:}

(1) Answers will be published in the SMJ February 2015 issue. (2) The MCR numbers of successful candidates will be posted online at the SMJ website by 6 April 2015. (3) Passing mark is $60 \%$. No mark will be deducted for incorrect answers. (4) The SMJ editorial office will submit the list of successful candidates to the Singapore Medical Council. (5) One CME point is awarded for successful candidates.

Deadline for submission: (February 2015 SMJ 3B CME programme): 12 noon, 27 March 2015. 